Nuit blanche

\title{
La littérature brésilienne
}

Michel Peterson

Numéro 76, automne 1999

La littérature brésilienne

URI : https://id.erudit.org/iderudit/19355ac

Aller au sommaire du numéro

Éditeur(s)

Nuit blanche, le magazine du livre

ISSN

0823-2490 (imprimé)

1923-3191 (numérique)

Découvrir la revue

Citer ce document

Peterson, M. (1999). La littérature brésilienne. Nuit blanche, (76), 32-33.

Ce document est protégé par la loi sur le droit d'auteur. L'utilisation des services d'Érudit (y compris la reproduction) est assujettie à sa politique d'utilisation que vous pouvez consulter en ligne.

https://apropos.erudit.org/fr/usagers/politique-dutilisation/
Cet article est diffusé et préservé par Érudit.

Érudit est un consortium interuniversitaire sans but lucratif composé de l'Université de Montréal, l'Université Laval et l'Université du Québec à Montréal. Il a pour mission la promotion et la valorisation de la recherche. https://www.erudit.org/fr/ 


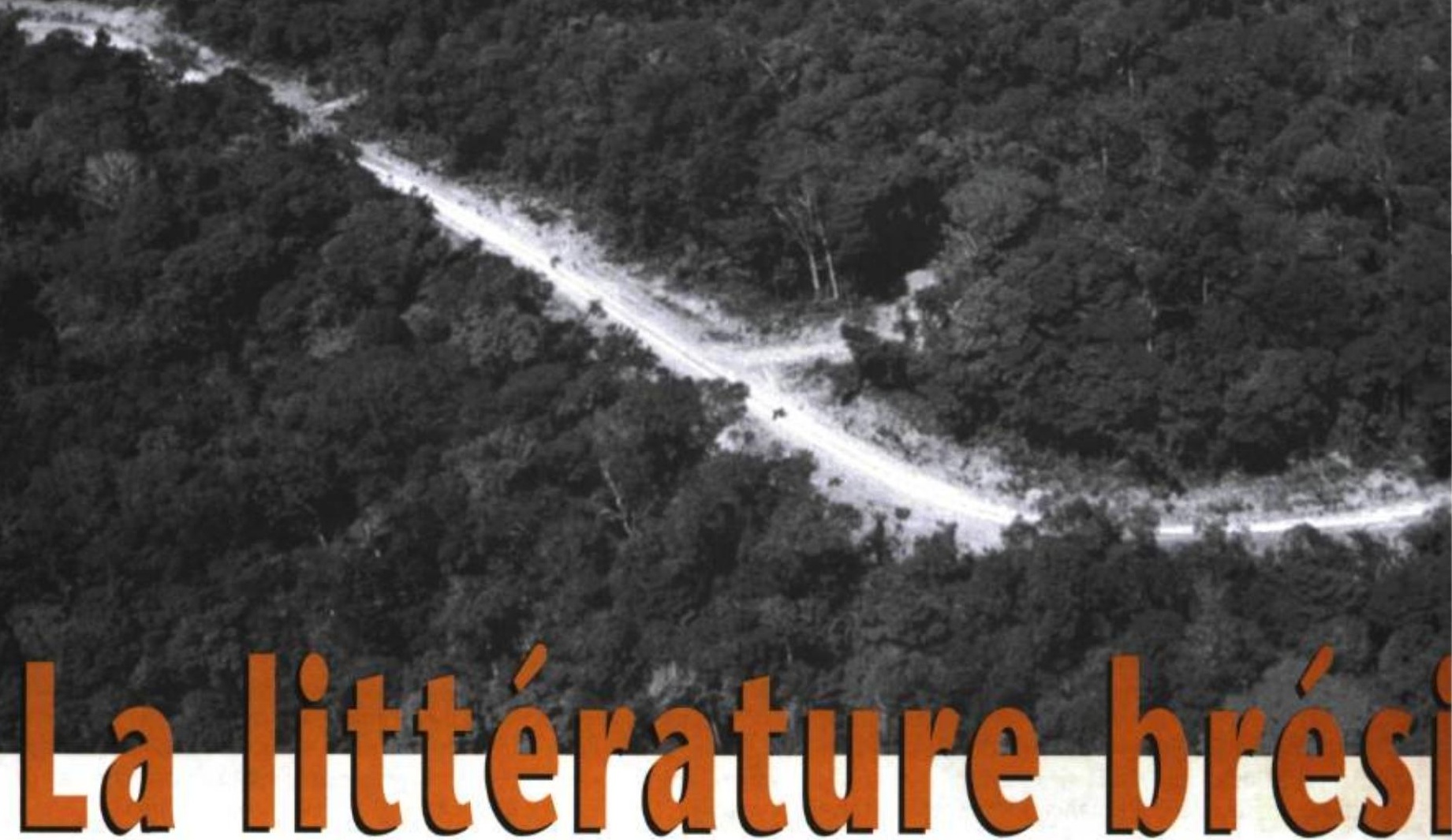

Le Brésil n'est qu'un goinfre. Aussi insatiable que ses terres extrêmes, sereinement inondées par les astres, il ouvre grand la gueule pour dévorer toute matière qui s'en approche, animale, végétale, minérale ou spectrale. L'être humain, sybarite, n'échappe pas à l'imposante dévoration. Intriguant paradoxe que ce pays de tous les fantasmes multiplie la famine sur un air de samba, comme si l'imaginaire du Divin Capital avait trouvé là son actualisation la plus démoniaque. Manger à en vomir ou vomir de ne jamais manger à sa faim : deux pôles plantureux de misère qui finissent par copuler dans les replis de l'Amazone, de la mer, des montagnes, des terres sèches du sertão et des lagunes du Sud. La littérature brésilienne connaît si intimement l'injustice et la corruption qui forment le tuf de la société l'hébergeant qu'elle les traite avec une joie responsable en méprisant le tragique. Même les écrivains les plus austères cultivent, aux moments les plus aigus, le trait épigrammatique, voire la grivoiserie ou la pasquinade. Après tout, la chair de l'existant n'est-elle pas gorgée d'humeurs?

Une telle vision risque encore et malgré tout d'avaliser les mythes du métissage et de la démocratie raciale, du culte du soccer et du cul des naïades cariocas. Jusqu'à un certain point... seulement. Car tout cela est bel et bien vrai : les miracles de I'hybridation, le génie des Pélé et Ronaldo, les brioches dorées des adolescentes et les cuisses de Jupiter paradant sur les plages. Le touriste qui se croit futé, un verre à la main sur la terrasse de son hôtel bien protégé, ne manquera pas de faire remarquer combien il est dommage qu'une telle beauté soit grevée de violence, exploitée sans ménagement par des oligarchies arrogantes, paternalistes, machistes, 


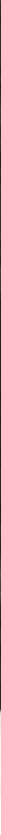

bandées sur le mensonge états-unien ou l'utopie européenne. II n'aura pas tort et aura ainsi conforté son ethnocentrisme et sa peur du rêve. Aura-t-il pour autant touché l'élément capital, c'est-à-dire l'exotisme, pas celui des cartes postales, pas celui de l'histoire, mais celui d'une identité assurant une jouissance de tous les instants à travers laquelle s'élabore la vie sensuelle des signes, des espoirs et des corps les plus fous. Le psychanalyste Octavio Souza remarquait judicieusement que le Brésil, contrairement à notre puritaine et rigoriste Amérique, n’a pas à construire de paradis dans le futur puisqu'il est le paradis depuis toujours, bien avant son invention moderne par l'Europe. Soyons clairs : Souza ne dit pas que paradis et bordel sont synonymes. D'ailleurs, les bâtiments ne se ressemblent pas. II dit plutôt et à peu près que le bonheur, fantaisie sublime, consiste peut-être à laisser venir à soi et pour l'autre le goût du monde et des choses. De quoi fomenter une révolution des esprits. Chaque texte de ce dossier illustre que notre raison n'a aucune raison d'être dans le pays de l'ordre et du progrès. Descartes n'y a-t-il pas perdu son latin? D'où le plaisir absolu de savourer les plats brésiliens.

Par Michel Peterson*

${ }^{*}$ C'est à Michel Peterson, professeur de théorie littéraire à l'Université fédérale de Rio Grande do Sul (Porto Alegre), que l'on doit la préparation du dossier sur la littérature brésilienne, de même que la révision de plusieurs textes qui en font partie. Un grand merci. Pour réussir ce travail de taille, Michel Peterson a obtenu la collaboration généreuse et amicale de Véra Lucia dos Reis, professeure à l'Université fédérale Fluminense de Rio de Janeiro, et d'Ignacio Antonio Neis, professeur titulaire de littérature et de linguistique à l'Université fédérale du Rio Grande do Sul (Porto Alegre). Qu'ils acceptent sa reconnaissance et la nôtre.

Nuit Blanche tient également à remercier tous les collaborateurs qui ont participé à la réalisation du dossier. 